\title{
The magic of medicine
}

\author{
Kamran Abbasi \\ Editor, JRSM \\ E-mail: kamran.abbasi@rsm.ac.uk
}

The debate on whether medicine is an art or science is as old as medicine itself, but is it magic? 'Mystery, magic and medicine,' observed Howard Haggard, 'in the beginning they were one and the same.' Although doctors and magicians have since parted ways, explains Daniel Sokol in this month's JRSM, they both want to leave their 'client' better off than when they met (JRSM 2008;101:443-446).

For a magician this is the greater feat, as the client's initial view is one of suspicion and distrust, a desire to expose the magician's trickery. A talented magician will leave you aghast at the sleight of hand that has occurred but a talented doctor might persuade you to consent to a procedure or change of lifestyle. Sokol, a magician and medical ethicist, proposes that magicians and doctors both practice deception but in different environments.

His central argument is that doctors have much to learn from magicians. Both groups, he says, deal with people in an intimate and intense context, striving to effect a positive change in their audience. Both possess skills that their patients or audience do not have. And, crucially, they both rely heavily on trust, fairness and clear communication for success.

Yet verbal and non-verbal communications the arts of a magician or clinician - are no longer sufficient to fully inform patients, although they are vital elements. Our information-rich, interconnected world makes it harder for clinicians to gather all the information required for a single consultation, while placing high literacy demands on patients; indeed, the greatest demands are often placed on the patients who are least well equipped in terms of literacy. Around $20 \%$ of patients will have too low a level of health literacy to understand health information provided to them.

Patient information leaflets can be useful but are insufficient to support doctors in their day-today practice as patients, like any group of learners, will learn best in different ways and via different formats and media. Anthea Colledge and colleagues explore the landscape beyond patient information leaflets and find a rich and varied landscape that requires further evaluation but is already showing promise (JRSM 2008;101: 447-453).

Health professionals and health services, argue these authors, have an important role to play in guiding patients to high-quality information and supporting their access to that information. But that information is increasingly delivered by different methods. We already have some evidence for success of pictograms and pictures alongside written information, multimedia games for children, audio recording of consultations, text messaging, DVDs and websites. These are all tricks that doctors can pull out of their magician's hats but they all require skill, patience and hard work to master and deliver effectively. If you can't be bothered with all this complication of medical practice and find hard to know where to begin with all this prestidigitation, you may find solace in Richard Smith's piece on the value of procrastination (JRSM 2008;101:478). 